\title{
Efficiency of cold passover and heated humidification under continuous positive airway pressure
}

\author{
W.J. Randerath*, J. Meier ${ }^{\#}$, H. Genger*, U. Domanski*, K-H. Rühle*
}

Efficiency of cold passover and heated humidification under continuous positive airway pressure. W.J. Randerath, J. Meier, H. Genger, U. Domanski, K-H.Rühle. (C)ERS Journals Ltd 2002.

ABSTRACT: Cold passover and heated humidifiers are employed for the prevention of side-effects associated with continuous positive airway pressure (CPAP) treatment. However, to date, it has not been possible to separately measure the humidity of inspired and expired air. The aim of this study was to compare the relative humidity of the inspired air and the water loss during respiration between cold passover and heated humidifiers under CPAP.

Humidity and temperature were determined separately for the respiratory phases, without humidification, with cold passover and heated humidifiers in $\mathbf{1 0}$ healthy subjects. Humidity was measured with a capacitive hygrometer, temperature with a "Type K" thermosensor, and impedance of the total respiratory system with impulse oscillometry.

The relative humidity $(\mathrm{rH})$ of the inspired air (mean \pm SD) increased significantly from $24.0 \pm 9.1 \% \mathrm{rH}\left(34.8 \pm 1.0^{\circ} \mathrm{C}\right.$, no humidifier) to $34.5 \pm 10.1 \% \mathrm{rH}\left(34.6 \pm 1.0^{\circ} \mathrm{C}\right)$ under cold humidification, and to $53.9 \pm 13.2 \% \mathrm{rH}(35.0 \pm 1.1 \mathrm{C})$ under heated humidification. With heated humidification, water loss was reduced by $38 \%$ compared to cold humidification. The impedance increased from $5.7 \pm 1.8 \mathrm{cmH}_{2} \mathrm{O} \cdot \mathrm{L} \cdot \mathrm{s}^{-1}$ (no humidifier) to $6.7 \pm 1.8 \mathrm{cmH}_{2} \mathrm{O} \cdot \mathrm{L} \cdot \mathrm{s}^{-1}$ (heated humidifier).

The authors conclude that the use of a heated humidifier during continuous positive airway pressure appreciably increases the relative humidity of the inspired air and reduces the water loss during respiration.

Eur Respir J 2002; 20: 183-186.
*Dept of Pneumology, Allergology and Sleep Medicine, University Witten/ Herdecke, and ${ }^{\#}$ Medizintechnik für Arzt und Patient (MAP), Martinsried, Germany.

Correspondence: W.J. Randerath, Klinik Ambrock, Dept of Pneumology, Allergology and Sleep Medicine, Ambrocker Weg 60, 58091 Hagen, Germany. Fax: 492331974209

E-mail: winfried.randerath@dland.de

Keywords: Apnoea

breath tests

humidity

positive pressure ventilation

respiratory system

Received: August 12001

Accepted after revision: February 18 2002

This study was supported by the MAP, Martinsried, Germany.
The use of humidifiers is recommended for the treatment of local side-effects associated with nasal continuous positive airway pressure (nCPAP) therapy to increase the humidity and temperature of the respired air [1-4]. To date, however, only humidity data averaged over a lengthy period of time have been reported $[5,6]$. Humidifiers are thought to exert an effect by changing the inspired air. Separate measurement of humidity during inspiration and expiration appears to be particularly useful as, owing to the high expiratory humidity, averaging of humidity figures over lengthy periods cannot completely reveal the effect of humidification on inspired air. Therefore, the present authors studied the influence of humidification under continuous positive airway pressure (CPAP) using sensors with a small dead time, making it possible to determine the rapid changes in humidity in the alternation of inspiration and expiration. The authors aimed to compare the relative humidity (Hrel) of the inspired air between cold passover and heated humidifiers, and to measure the water loss of respiration under CPAP treatment. A secondary aim was to evaluate the impedance $(Z)$ of the total respiratory system under the various humidification systems.

\begin{abstract}
Methods
Subjects

The study included 10 healthy subjects (six males and four females, mean \pm SD age $28.8 \pm 10 \mathrm{yrs}$, body mass index (BMI) $23.4 \pm 2.9 \mathrm{~kg} \cdot \mathrm{m}^{-2}$, no airway disease, rhinitis, nasal surgery, upper airways infections over the previous 4 weeks). Before the experiments, lung function (forced vital capacity (FVC) 109.9 $\pm 25.8 \%$ predicted, forced expiratory volume in one second (FEV1) $117.9 \pm 30.9 \%$ pred, total lung capacity (TLC) $108.2 \pm 17.4 \%$ pred) and nasal $Z$ were determined (body plethysmography was performed using Master Labß and impulse oscillometry using IOS RhinoR, both from Jaeger, Höchberg, Germany). The total $Z$ of the nose was calculated from separate measurements in both nares $\left(Z 5 \mathrm{~Hz} 4.7 \pm 2.4 \mathrm{cmH} \mathrm{H}_{2} \mathrm{O} \cdot \mathrm{L} \cdot \mathrm{s}^{-1}\right.$, resistance $(\mathrm{R}) 4.0 \pm 2.0$, reactance $(\mathrm{X})-2.0 \pm 2.0$ ) [7].
\end{abstract}

\section{Design}

The subjects were examined in randomised order in the supine position, at a CPAP pressure of $10 \mathrm{cmH}_{2} \mathrm{O}$ 
and in the wake state over three phases (without humidification (no $\mathrm{H}, 32.8 \pm 10.8 \mathrm{~min}$ ), with cold passover humidification (cold $\mathrm{H}, 36.4 \pm 7.5 \mathrm{~min}$ ), and with heated humidification (heated $\mathrm{H}, 54.3 \pm$ $12.5 \mathrm{~min})$ ) of $\geqslant 20 \mathrm{~min}$ of stable breathing each. The ambient temperature was $22.0 \pm 0.2^{\circ} \mathrm{C}$ and Hrel $29.6 \pm 2.3 \%$.

\section{Materials}

The subjects were connected via a nose mask

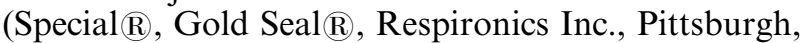
USA) to a CPAP device (fig. 1). This device incorporates a surface contact humidifier, which was used for cold $\mathrm{H}$ (water temperature $\leqslant$ ambient temperature) or heated $\mathrm{H}\left(>35^{\circ} \mathrm{C}\right)$ (CPAP with integrated humidifier: Max IIR, Medizintechnik für Arzt und Patient, Martinsried, Germany). The humidity of the air was measured with a capacitive hygrometer (custommade, University of Göttingen, Germany, range for 5-99\% rH [8]) between the mask and Y-adapter. This system incorporates a layer of plastic polymer, between two electrodes which, depending on the humidity, can adsorb water molecules. These bring about a change in the capacity, which is correlated with the humidity. The sensor is heated to prevent water condensation. The capacitive hygrometer has only a very low dead time, enabling changes in the humidity between inspired and expired air to be measured (time constant $0.23 \mathrm{~s}$ at $40^{\circ} \mathrm{C}, 0.18 \mathrm{~s}$ at $50^{\circ} \mathrm{C}$ and $0.14 \mathrm{~s}$ at $60^{\circ} \mathrm{C}$ ). The nonlinearity of the sensor was $\pm 0.1 \mathrm{mg} \cdot \mathrm{L}^{-1}$. The device was calibrated using a mirror-type dew point hygrometer (maximal error after calibration $\pm 0.6 \mathrm{mg} \cdot \mathrm{L}^{-1}$ ) [8]. Temperature was measured with a "Type $\mathrm{K}$ " thermosensor (range $-200-1,300^{\circ} \mathrm{C}$, tolerance $0.3 \%$ ) in the mask and a second thermosensor in the capacitive hygrometer. The authors applied the following data sets, recorded for $\sim 1$ min preceding each measurement of $Z$ of the total respiratory system, for the evaluation of humidity and temperature. Expiration: 632 data sets under no $\mathrm{H}, 430$ under cold $\mathrm{H}, 672$ under heated $\mathrm{H}$; inspiration: $633,434,660$, data sets respectively. $Z$ was determined every 5 min using impulse oscillometry (50 measurements under no $\mathrm{H}, 37$ with cold $\mathrm{H}$, and 60 with heated H (IOS, Jaeger, Höchberg, Germany); oscillating frequency $0-100 \mathrm{~Hz}$ ). Impulse oscillometry was employed for the lower and upper airways [7, 9] and the forced oscillation technique proved to be useful in the diagnosis and automatic treatment of obstructive sleep apnoea syndrome (OSAS) [10-13]. Flow was measured with a laminar flow element LFE-Typ PT (SI, Nördlingen, Germany; $0-150 \mathrm{~L} \cdot \mathrm{min}^{-1}$, tolerance $<0.1 \%)$. The ambient conditions were determined with the hygrometer HP 100A (Rontronic, Bassersdorf, Switzerland; temperature $-20-60^{\circ} \mathrm{C}$, tolerance $0.3^{\circ} \mathrm{C}$, humidity $0-99 \% \mathrm{rH}$, tolerance $1.5 \% \mathrm{rH}$ ).

\section{Definitions}

Hrel defines the actual amount of water contained in a gas in relation to the maximum possible amount it can contain, and depends on the temperature of the gas. Hrel can be calculated from the absolute humidity

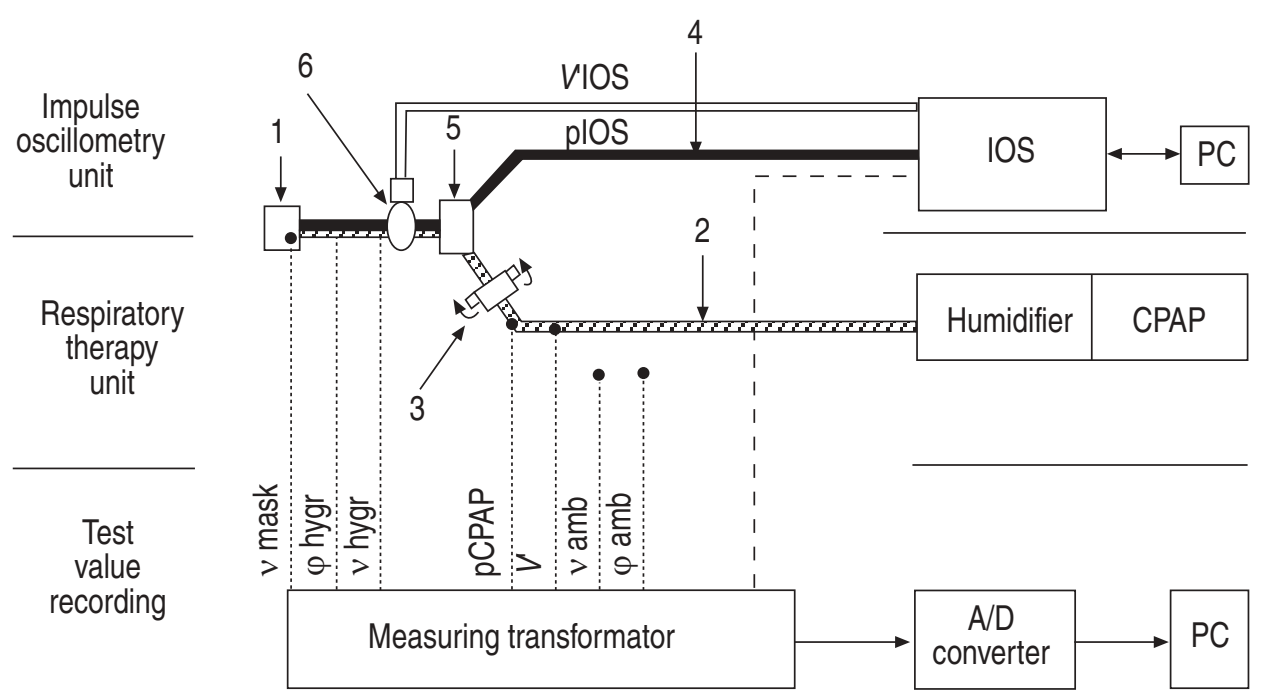

Fig. 1.-Schematic representation of the set-up used for the measurements. The measurement set-up comprises three modules: the impulse oscillometry for the measurement of impedance; the respiratory therapy unit; and the unit for data acquisition and processing. The subject is connected to the continuous positive airway pressure (CPAP) device and the humidifier via a nasal mask (1) and a tube system (2). The temperature of the respired air is measured within the mask ( $v$ mask) and the hygrometer ( $v$ hygr). Within the breathing tube there is another, small-calibre tube that transmits the pressure in the nose mask to the sensor in the CPAP device. The capacitive hygrometer for measuring the humidity in inspired and expired air ( $\varphi$ hygr) is located between mask and breathing tube. A valve serves to eliminate the expired carbon dioxide (3). In the impulse oscillometry unit (impulse oscillometry (IOS) device), an oscillating flow is generated and conducted, via a tube (4) and Y-adapter (5), to the airways. The IOS device also picks up the pressure (pIOS) and flow (vIOS) signals recorded by the pneumotachograph (6) and filters out the signals produced by the oscillating flow. These signals are used to calculate the impedance. The transducer picks up all the measuring signals in the tube system and from the surroundings, and passes them, via an analogue-to-digital converter (A/D converter), to the computer (PC). pCPAP: pressure measured in the breathing tube; $V^{\prime}$ : flow measured in the breathing tube; $\varphi$ amb: humidity of the ambient air; $v$ amb: temperature of the ambient air. 
and temperature with a 4th degree polynomial, which represents an approximation of the water content curve (Equation 1) [8].

$$
\text { Hrel }(\% \mathrm{rH})=\frac{\mathrm{Habs}_{\mathrm{a}} \times 100}{\left(\alpha_{4} v^{4}+\alpha_{3} v^{3}+\alpha_{2} v^{2}+\alpha_{1} v^{1}+\alpha_{0}\right)}
$$

Where: $\alpha_{4}: 2.06448 \times 10^{-6} \mathrm{mg} \cdot \mathrm{L}^{-6}{ }^{\circ} \mathrm{C}^{-1} ; \alpha_{3}: 1.83498 \times$ $10^{-4} \mathrm{mg} \cdot \mathrm{L}^{-4}{ }^{\circ} \mathrm{C}^{-1} ; \quad \alpha_{2}: \quad 9.92897 \times 10^{-3} \mathrm{mg} \cdot \mathrm{L}^{-3}{ }^{\circ} \mathrm{C}^{-1} ; \quad \alpha_{1}$ : $3.3282 \times 10^{-1} \mathrm{mg} \cdot \mathrm{L}^{-1}{ }^{\circ} \mathrm{C}^{-1} ; \alpha_{0}: 4.8681 \mathrm{mg} \cdot \mathrm{L}^{-1} ; \mathrm{v}:$ temperature $\left({ }^{\circ} \mathrm{C}\right)$, Habs: absolute humidity $\left(\mathrm{mg} \cdot \mathrm{L}^{-1}\right)$, Hrel $(\% \mathrm{rH})$ : relative humidity.

The water loss during respiration (Wloss) can be calculated from the difference in Habs between inspired and expired air.

$$
\begin{aligned}
\text { WLoss }\left(\mathrm{mg} \cdot \min ^{-1}\right)= & (\text { Habs }(\text { expiration }) \\
& - \text { Habs (inspiration })) \times V^{\prime} \mathrm{E}
\end{aligned}
$$

Where $V^{\prime} \mathrm{E}$ is minute ventilation $\left(\mathrm{L} \cdot \mathrm{min}^{-1}\right)$.

\section{Statistics}

All data are presented as mean $\pm \mathrm{SD}$. The computations for significant differences at $p<0.05$ were performed using a repeated-measure one-way analysis of variance (ANOVA) with post hoc comparisons (Bonferroni post hoc test).

\section{Results}

Hrel of the inspired air with no $\mathrm{H}$ increased under cold $\mathrm{H}$, but more so under heated $\mathrm{H}$ (table 1 ). In the expired air, Hrel showed only mild, but significant, increases with both humidification modes. With no $\mathrm{H}$, the difference in absolute humidity between inspired and expired air was $21.5 \pm 4.7 \mathrm{mg} \cdot \mathrm{L}^{-1}$. This was reduced under cold $\mathrm{H}$ to $18.8 \pm 4.6 \mathrm{mg} \cdot \mathrm{L}^{-1} \quad(\mathrm{p}<0.01)$ and under heated $\mathrm{H}$ to $12.3 \pm 5.1 \mathrm{mg} \cdot \mathrm{L}^{-1}(\mathrm{p}<0.001$ as compared with cold $\mathrm{H}$ and no $\mathrm{H}$ ). Thus, the loss of water under no $\mathrm{H}$ was only slightly reduced under cold $\mathrm{H}$, but was halved under heated $\mathrm{H}(38 \%$ decrease of the water loss under heated $\mathrm{H}$ compared to cold $\mathrm{H}$ ) (table 1). The $Z$ of the total respiratory system increased under heated $\mathrm{H}$ (table 1).

\section{Discussion}

In the present study the humidity of respired air for inspiration and expiration were measured separately for the first time. Earlier data were only average figures obtained over several respiratory cycles $[5,6]$. Although the inspired air was influenced by the humidifier, the figures reported were of the same order as those measured for expired air [6]. The measurement of humidity can be considerably falsified by condensation of water on the sensors. This was likely with values of Hrel approaching 100\% [8]. To avoid this effect, the present study used a heated hygrometer. A significant increase in inspiratory humidity was found through the use of cold and heated $\mathrm{H}$. However, a clinically relevant increase in Hrel was only seen under heated $\mathrm{H}$. In expired air, small differences in Hrel were observed between the various humidification systems. The low level of

\begin{tabular}{|c|c|c|c|c|}
\hline Parameter & No humidifier & Cold humidifier & Heated humidifier & p-value \\
\hline \multicolumn{5}{|l|}{ Inspiration } \\
\hline Hrel \% & $24.0 \pm 9.1$ & $34.5 \pm 10.1^{\#}$ & $53.9 \pm 13.2^{\uparrow,+}$ & $<0.001$ \\
\hline Habs $\mathrm{mg} \cdot \mathrm{L}^{-1}$ & $9.4 \pm 3.5$ & $13.4 \pm 3.9^{\#}$ & $21.3 \pm 5.1^{\boldsymbol{\top},+}$ & $<0.001$ \\
\hline v hygrometer ${ }^{\circ} \mathrm{C}$ & $34.8 \pm 1.0$ & $34.6 \pm 1.0^{\#}$ & $35.0 \pm 1.1^{\uparrow,+}$ & $<0.001$ \\
\hline$v$ mask ${ }^{\circ} \mathrm{C}$ & $31.1 \pm 1.4$ & $31.3 \pm 1.6$ & $32.4 \pm 1.7^{\sigma^{\top},+}$ & $<0.001$ \\
\hline \multicolumn{5}{|l|}{ Expiration } \\
\hline Hrel \% & $75.5 \pm 14.4$ & $79.8 \pm 10.2^{\#}$ & $82.2 \pm 8.9^{\top,+}$ & $<0.001$ \\
\hline Habs $\mathrm{mg} \cdot \mathrm{L}^{-1}$ & $30.8 \pm 5.5$ & $32.2 \pm 4.0^{\#}$ & $33.6 \pm 3.5^{\uparrow,+}$ & $<0.001$ \\
\hline$v$ hygrometer ${ }^{\circ} \mathrm{C}$ & $35.6 \pm 0.7$ & $35.3 \pm 0.9^{\#}$ & $35.6 \pm 0.9^{\bullet,+}$ & $<0.001$ \\
\hline v mask ${ }^{\circ} \mathrm{C}$ & $32.4 \pm 1.1$ & $32.6 \pm 1.2^{\#}$ & $33.7 \pm 1.1^{\uparrow,+}$ & $<0.001$ \\
\hline$V \mathrm{~T} \mathrm{~L}$ & $0.58 \pm 0.37$ & $0.59 \pm 0.37$ & $0.81 \pm 1.5$ & 0.42 \\
\hline $\mathrm{Bf} \mathrm{L} \cdot \mathrm{min}^{-1}$ & $21.9 \pm 10.2$ & $21.2 \pm 10.2$ & $18.9 \pm 9.9$ & 0.26 \\
\hline$V \mathrm{E} \mathrm{L} \cdot \mathrm{min}^{-1}$ & $10.5 \pm 4.0$ & $10.1 \pm 4.4$ & $9.6 \pm 3.2$ & 0.43 \\
\hline Water loss $\mathrm{mg} \cdot \mathrm{min}^{-1}$ & $226.3 \pm 49.4$ & $190.8 \pm 46.9^{\#}$ & $118.0 \pm 48.5^{\top,+}$ & $<0.001$ \\
\hline \multicolumn{5}{|l|}{ Impedance of the total } \\
\hline $\begin{array}{l}\text { respiratory system } \\
\quad Z 5 \mathrm{~Hz} \mathrm{cmH}{ }_{2} \mathrm{O} \cdot \mathrm{L}^{-1} \cdot \mathrm{s}^{-1}\end{array}$ & $5.7 \pm 1.8$ & $6.4 \pm 2.1$ & $6.7 \pm 1.8^{\circ}$ & 0.025 \\
\hline $\mathrm{R} 5 \mathrm{~Hz} \mathrm{cmH}_{2} \mathrm{O} \cdot \mathrm{L}^{-1} \cdot \mathrm{s}^{-1}$ & $5.5 \pm 1.4$ & $6.1 \pm 1.7$ & $6.3 \pm 1.5$ & 0.012 \\
\hline $\mathrm{R} 20 \mathrm{~Hz} \mathrm{cmH}_{2} \mathrm{O} \cdot \mathrm{L}^{-1} \cdot \mathrm{s}^{-1}$ & $5.4 \pm 0.7$ & $5.3 \pm 0.7$ & $5.3 \pm 0.6$ & 0.62 \\
\hline $\mathrm{X} 5 \mathrm{~Hz} \mathrm{cmH}_{2} \mathrm{O} \cdot \mathrm{L}^{-1} \cdot \mathrm{s}^{-1}$ & $-1.7 \pm 1.3$ & $-2.1 \pm 1.4$ & $-2.1 \pm 1.2$ & 0.21 \\
\hline
\end{tabular}
expiratory Hrel appeared to be due to both the

Table 1.-Humidity and water loss

Hrel: relative humidity; Habs: measured absolute humidity in the capacitive hygrometer; $v$ hygrometer: temperature in the hygrometer; $v$ mask: temperature in the mask; $V \mathrm{~T}$ : tidal volume; Bf: breathing frequency; $V \mathrm{E}$ : minute volume; water loss: amount of water lost on the basis of measurements of absolute humidity in expired and inspired air; Z $5 \mathrm{~Hz}$ : impedance of the total respiratory system at an oscillation frequency of $5 \mathrm{~Hz}$; R $5 \mathrm{~Hz}$ : resistance at $5 \mathrm{~Hz}$; R $20 \mathrm{~Hz}$ : resistance at $20 \mathrm{~Hz}$; X $5 \mathrm{~Hz}$. reactance at $5 \mathrm{~Hz}$. The p-values were determined according to the repeated-measure one-way analysis of variance $(\mathrm{p}<0.05)$. The post hoc significance: ${ }^{*}$ : cold humidifier versus no humidifier; ${ }^{+}$: heated humidifier versus cold humidifier; ": heated humidifier versus no humidifier. 
distance between the sensor and the nose and the reservoir function of the nose mask. The amount of water lost on respiring nonhumidified air decreased by $16 \%$ with cold $\mathrm{H}$, but by $44 \%$ with heated $\mathrm{H}$. Since separate measurements of inspiratory and expiratory Hrel were not possible previously, comparable data on water loss are not available. Despite pronounced differences, all studies show that humidifiers increase humidity. Heated $\mathrm{H}$ has a clearly greater effect than cold $\mathrm{H}[5,6]$. Compared with CPAP under no $\mathrm{H}$, MAssie et al. [4] found that CPAP was utilised longer with heated $\mathrm{H}$, but not with cold $\mathrm{H}$.

Nasal obstruction is one of the major side-effects of continuous positive airway pressure treatment. Therefore, the possibility that the upper airways' impedance might be influenced differently by the various modes of humidification was investigated. The forced oscillation technique has proven useful in measuring the total airway system impedance under continuous positive airway pressure $[10,11]$. In the present study, it was measured with an impulse oscillometry device, selected because it does not require patient cooperation or, in contrast to posterior rhinomanometry, the introduction of a tube into the throat. Using posterior rhinomanometry, RICHARDS et al. [3] obtained appreciably lower baseline measurements, which might have been due to differences in methodology. The present data showed no clinically relevant changes in impedance under the various humidification systems, and all measurements were carried out with the patient breathing quietly with the mouth closed. The small elevation in impedance under heated humidification compared to no humidification may have been due to the longer period of heated humidification $(54.3 \pm 12.5$ versus $32.8 \pm 10.8 \mathrm{~min})$ and/ or the kind of humidification system used. The present study provides no data on the long-term use of humidification systems and therefore, the conclusions presented cannot be related to long-term overnight use of humidification. Moreover, because the study was specifically designed to compare relative humidity of the inspired air under cold and heated humidification and to measure water loss in healthy subjects in the wake state and at a continuous positive airway pressure of $10 \mathrm{cmH}_{2} \mathrm{O}$, the results cannot be translated to other specific situations (e.g. mouth leaks, different pressure levels and ambient conditions).

\section{References}

1. Pepin JL, Leger P, Veale D, Langevin B, Robert D, Levy P. Side effects of nasal continuous positive airway pressure in sleep apnea syndrome. Study of 193 patients in two French sleep centers. Chest 1995; 107: $375-381$.

2. Strohl KP, Arnold JL, Decker MJ, Hoekje PJ, McFadden ER. Nasal flow-resistive responses to challenge with cold dry air. J Appl Physiol 1992; 72: $1243-1246$.

3. Richards GN, Cistulli PA, Ungar RG, Berthon-Jones M, Sullivan CE. Mouth leak with nasal continuous positive airway pressure increases nasal airway resistance. Am J Respir Crit Care Med 1996; 154: 182186.

4. Massie CA, Hart RW, Peralez K, Richards GN. Effects of humidification on nasal symptoms and compliance in sleep apnea patients using continuous positive airway pressure. Chest 1999; 116: 403408.

5. Martins De Aranjo M, Vieira SB, Vasquez EC, Fleury B. Heated humidification or face mask to prevent upper airway dryness during continuous positive airway pressure therapy. Chest 2000; 117: 142-147.

6. Wiest GH, Fuchs FS, Brueckl WM, et al. In vivo efficacy of heated and non-heated humidifiers during nasal continuous positive airway pressure (nCPAP)therapy for obstructive sleep apnoea. Respir Med 2000; 94: 364-368.

7. Randerath W, Smith HJ, Knarr D, Rühle KH. Comparison of anterior rhinomanometry and forced oscillation impulse technique in nasal provocation test with histamine. Pneumology 1998; 52: 97-103.

8. Rathgeber J, Kahle G, Schulze T, Züchner K. Schnelle Messung des Wasserdampfpartialdrucks im Sättigungsbereich mit einem neuartigen HybridFeuchte-Sensor. Biomed Technik 2000; 45: 288-292.

9. DuBois $\mathrm{AB}$, Brody $\mathrm{AW}$, Lewis $\mathrm{DH}$, Burgess $\mathrm{BF}$. Oscillation mechanics of lungs and chest in man. J Appl Physiol 1956; 8: 587-594.

10. Farré R, Rotger M, Montserrat JM, Navajas D. A system to generate simultaneous forced oscillation and continuous positive airway pressure. Eur Respir $J$ 1997; 10: 1349-1353.

11. Farré R, Rigau J, Montserrat JM, Ballester E, Navajas D. Evaluation of a simplified oscillation technique for assessing airway obstruction in sleep apnoea. Eur Respir J 2001; 17: 456-461.

12. Randerath W, Parys K, Feldmeyer F, Rühle KH. Self-adjusting nCPAP-therapy based on measurement of impedance - a comparison of two different maximum pressure levels. Chest 1999; 116: 991999.

13. Randerath W, Schräder O, Galetke W, Feldmeyer F, Rühle KH. Auto-adjusting CPAP therapy based on impedance. Efficacy, compliance and acceptance. $\mathrm{Am}$ J Respir Crit Care Med 2001; 163: 652-657. 